\title{
Fracture Surfaces and Mechanical Properties in Ductile Iron
}

\author{
V. M. BERMONT, R. N. CASTILLO and J. A. SIKORA ${ }^{11}$ \\ Mechanical Engineering Department, Faculty of Engineering, University of La Serena, Benavente 980 - La Serena, Chile. \\ E-mail: vbermont@userena.cl 1 1) Metallurgy Division, INTEMA, Faculty of Engineering, National University of Mar del \\ Plata, Juan B. Justo 4302 (7600) - Mar del Plata. Argentina.
}

(Received on March 28, 2002; accepted in final form on July 31, 2002)

\begin{abstract}
This work focuses on qualitative and quantitative studies about the fracture surface topography of ductile cast iron samples having different matrices and sizes.

Parameters such as: a) surface roughness, b) actual fracture surface and c) actual nodule count on fracture surface were defined and calculated for fracture surfaces of several experimental test samples. These parameters were related to the values of mechanical properties measured on the same samples, and empirical expressions were established. These expressions, together with data taken from the fracture surface of a broken part, could allow to estimate the critical level of stress and deformation which acted on the part.
\end{abstract}

KEY WORDS: ductile iron; fracture surfaces; mechanical properties; degree of roughness.

\section{Introduction}

Studies on actual fracture surfaces of most metallic pieces allow to explain the micromechanisms taking place. In most cast irons, the heterogeneity produced by the presence of graphite, microsegregated zones, and inclusions, allow the simultaneous development of various fracture mechanisms, which makes its interpretation more complex than for the case of steels.

Some studies about fracture profiles characterization for grey cast iron, as well as the participation of graphite nodules in the development of fatigue cracks for ductile iron, had been published. ${ }^{1-3)}$ Other studies show differences in the roughness, and in the number of graphite nodules contained on the fracture surfaces, associating them with changes in the matrix and loading history. ${ }^{4,5}$ However, qualitative and quantitative characterizations of fracture profiles and surfaces, and their relationships with mechanical properties have not been sufficiently studied for ductile iron, to the best of our knowledge. This can be due to the difficulties in applying quantitative techniques to fracture surfaces of these materials.

The main objective of the present work is to characterise and to quantify the degree of roughness of fracture surfaces of different samples of ductile iron through simple fractographic experimental analysis, in order to develop methods and models which could allow to estimate the critical level of stress and elongation acting in actual parts.

\section{Experimental Procedure}

The material used in this study was a ductile cast iron industrial melt, produced in a cupola furnace. The melt had the following chemical composition (wt \%): $\mathrm{C}=3.36, \mathrm{Si}=$ 2.52, $\mathrm{Mg}=0.029, \mathrm{Mn}=0.21, \mathrm{~S}=0.01, \mathrm{Cu}=0.82, \mathrm{Ni}=0.27$.
Y-blocks 1/2, 1 and 2 inches in thickness (ASTM A395) were cast in green sand moulds. From each Y-block size, oversized cylindrical and prismatic bars were machined. Four sets of 3 cylinders and 3 bars of each Y-block size were then heat treated in order to obtain a variety of matrix microstructures.

The following heat treatments were carried out on oversized cylindrical and prismatic bars: a) subcritical annealing at $680^{\circ} \mathrm{C}$ during $48 \mathrm{~h}$, to obtain a fully ferritic matrix; b) normalizing, by austenitizing at $900^{\circ} \mathrm{C}$ followed by air cooling, to obtain a fully pearlitic matrix; c) Austenitizing at $900^{\circ} \mathrm{C}$, followed by austempering in salt bath at $360^{\circ} \mathrm{C}$ during $90 \mathrm{~min}$, to obtain an ausferritic matrix, typical of an Austempered Ductile Iron (indicated as ADI and corresponding to an ADI Grade 2, ASTM897-90); d) Austenitizing at $920^{\circ} \mathrm{C}$, followed by austempering in salt bath at $280^{\circ} \mathrm{C}$ during $90 \mathrm{~min}$, to obtain an austenobainitic matrix indicated as ABDI (corresponding to an ADI Grade 4, ASTM897-90). The typical microstructures are shown in Fig. 1.

From the heat treated cylindrical and prismatic bars, tensile (ASTM A536) and fracture toughness test samples SENT (ASTM E399) were made, respectivelly. The shape and final dimensions of the samples are shown in the Fig. 2. A dynamic $15 \mathrm{~Hz}$ rotating eccentric actuator machine was used for the fatigue precracking of the fracture toughness test samples. In these samples, two markedly different types of fractured areas were observed, that is, the fatigue zone and the rapid fracture zone. Both the tensile and the SENT samples were tested in a Mohr and Federhaff servohydraulic machine with self-aligning jaws. Tensile and fracture toughness experimental values summarized in the tables are the averages of at least three test results. 


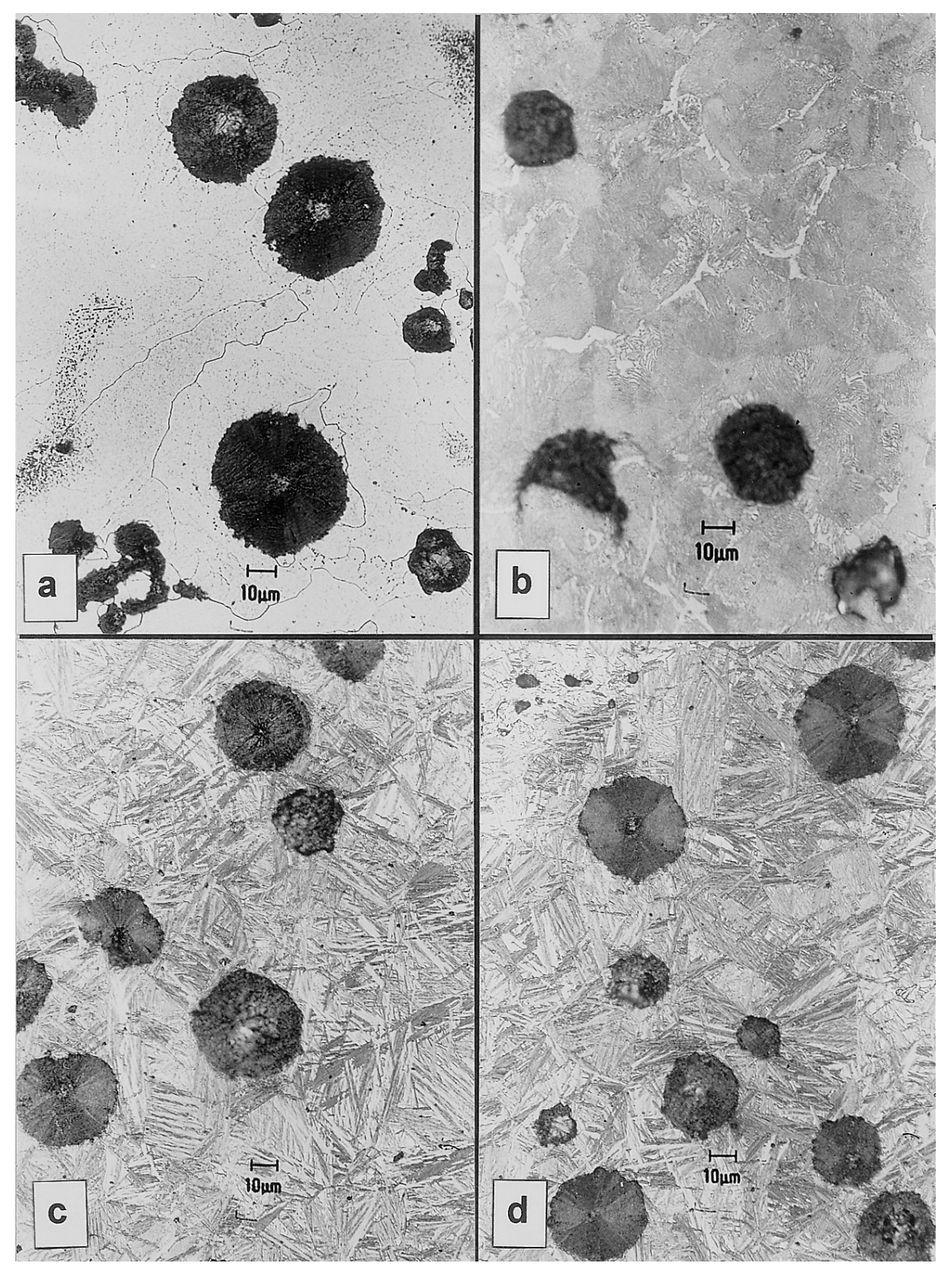

Fig. 1. Typical microstructures: a) ferritic matrix, b) pearlitic matrix, c) ausferritic matrix (ADI) and d) austenobainitic matrix (ABDI).

\subsection{Fracture Surfaces Roughness Parameters}

In order to define the fracture surface parameters the Underwood criteria ${ }^{6,7)}$ was used. A scheme of the parameters is shown in Fig. 3 for both tensile and fracture toughness test samples.

The roughness profile of the fracture surface " $R L$ " is defined as follows:

$$
R L(\mathrm{~mm} / \mathrm{mm})=\frac{L t}{L^{\prime}}
$$

In Eq. (1), " $L t$ " is the actual profile length, measured on the observation face (Figs. 3a) to 3d)), while " $L$ '" is the projected length on the same observation face (Figs. 3a), $3 c$ ) and 3d)).

Both " $L t$ " and " $L$ "' were obtained by manual measurements carried out on printed out computer pictures corresponding to the fracture surface profiles, as shown in Fig. 4. The printed out picture profiles correspond to X300 enlargement.

According to Underwood, ${ }^{6,7)}$ a fracture surface roughness parameter " $R s$ " is related to the roughness profile " $R L$ " as follows:

$$
R s=\left(\frac{4}{\pi}\right)(R L-1)+1
$$

The values of " $R L$ " are determined according to Eq. (1) by using the profiles optically observed on the polished areas obtained by sectioning, as shown schematically in Figs. 3a) and 3b). All reported values are the average of the profiles determined on 5 different levels of observation in each sample, separated by approximately $0.5 \mathrm{~mm}$ in depth (Fig. 3b)).

The roughness " $R s$ " was related to the magnitude of the actual fracture surface " $S t$ " and the projected surface " $S_{A}$ " (Fig. 3d)), as indicated in Eq. (3) (Underwood $\left.{ }^{6}\right)$.

$$
R s\left(\mathrm{~mm}^{2} / \mathrm{mm}^{2}\right)=\frac{S t}{S_{\mathrm{A}}}
$$




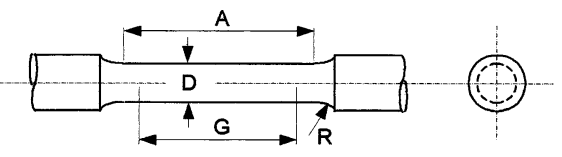

a) $A=32 \mathrm{~mm}, \mathrm{G}=25.4 \mathrm{~mm}, \mathrm{D}=6.35 \mathrm{~mm}, \mathrm{R}=5 \mathrm{~mm}$

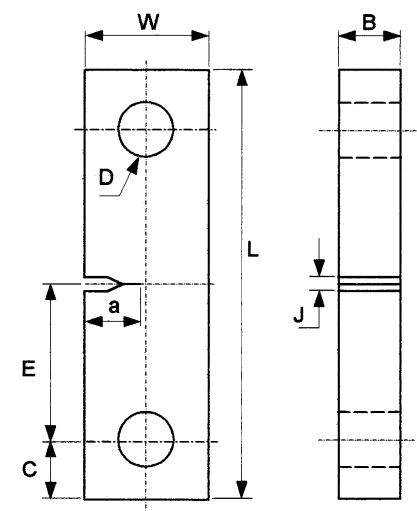

b) $B=10 \mathrm{~mm}, W=20 \mathrm{~mm}, a=9 \mathrm{~mm}, L=120 \mathrm{~mm}$,

b) $J=2 \mathrm{~mm}, E=50 \mathrm{~mm}, C=10 \mathrm{~mm}, D=9 \mathrm{~mm}$

Fig. 2. Shapes and dimensions of: a) tensile and b) fracture toughness test sample.

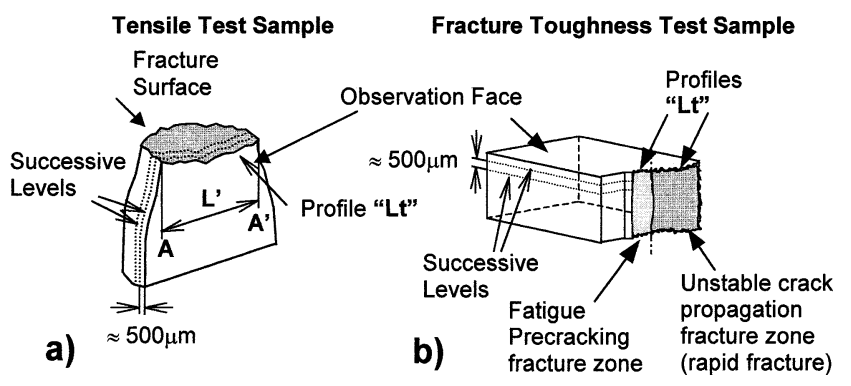

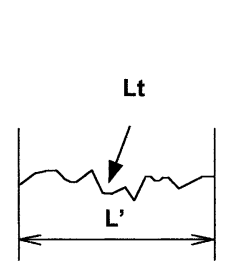

c)

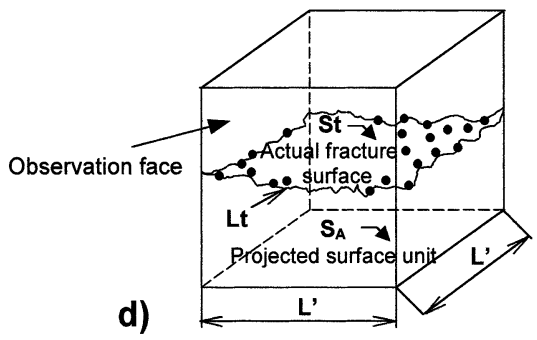

Fig. 3. Schematic representation of the fracture surfaces: a) tensile test and b) fracture toughness test sample. Schematic representation of the parameters: c) " $L t$ ", profile and d) " $S t$ ", actual fracture surfaces and " $S_{\mathrm{A}}$ " projected surface unit.

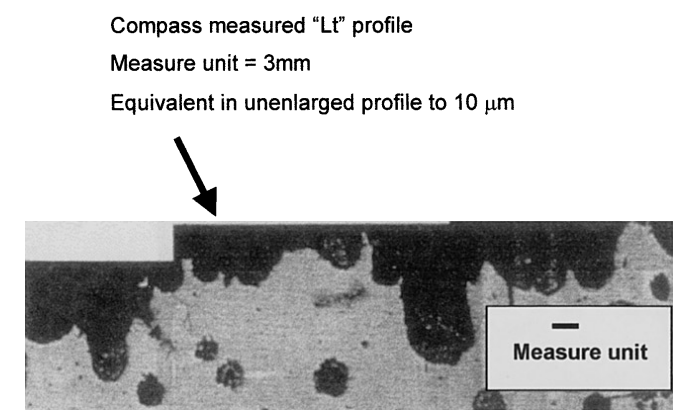

Fig. 4. Video camera captured image and printed out by inkjet printer. Enlargement scale $1: 300$.
Table 1. Summary of roughness experimental values for all types of test samples.

\begin{tabular}{cccccccc}
\hline Matrix & Size & \multicolumn{3}{c}{$\mathrm{RL}$} & & \multicolumn{3}{c}{ Rs } \\
& & Tensile & Fatigue & Rapid & Tensile & Fatigue & Rapid \\
\hline \multirow{3}{*}{ Ferritic } & $1 / 2 "$ & 1.97 & 1.28 & 1.88 & 2.24 & 1.36 & 2.12 \\
& $1 "$ & 1.88 & 1.20 & 1.82 & 2.12 & 1.25 & 2.04 \\
& $2 "$ & 1.82 & 1.16 & 1.79 & 2.04 & 1.21 & 2.01 \\
& $1 / 2 "$ & 1.23 & 1.09 & 1.22 & 1.30 & 1.11 & 1.28 \\
Pearlitic & $1 "$ & 1.20 & 1.08 & 1.19 & 1.26 & 1.10 & 1.24 \\
& $2 "$ & 1.17 & 1.07 & 1.16 & 1.22 & 1.09 & 1.20 \\
& $1 / 2 "$ & 1.53 & 1.18 & 1.47 & 1.67 & 1.23 & 1.60 \\
ADI & $1 "$ & 1.47 & 1.15 & 1.42 & 1.60 & 1.19 & 1.53 \\
& $2 "$ & 1.43 & 1.13 & 1.40 & 1.55 & 1.17 & 1.51 \\
& $1 / 2 "$ & 1.38 & 1.15 & 1.37 & 1.49 & 1.19 & 1.47 \\
ABDI & $1 "$ & 1.35 & 1.12 & 1.34 & 1.45 & 1.15 & 1.43 \\
& $2 "$ & 1.29 & 1.08 & 1.28 & 1.36 & 1.10 & 1.36 \\
\hline
\end{tabular}

By replacing the expression of " $R s$ " given by Eq. (3), in Eq. (2), considering that " $S_{\mathrm{A}}$ " is a $1 \mathrm{~mm}^{2}$ surface, the parameter " $R s$ " becomes equal to the value of the actual fracture surface " $S t$ ".

Considering that "St" is greater than " $S_{\mathrm{A}}$ ", the value of " $R s$ " will always be greater than 1 . Therefore, the greater the value of " $R s$ ", the greater the actual fracture surface " $S t$ ". In short, as it was explained before, " $R L$ " is obtained experimentally and " $S t$ " is calculated from Eq. (2).

\subsection{Effect of the Nodules on the Fracture Surfaces}

The fracture surface of ductile iron is composed of a mixture of fractured zones of the matrix and nodules of graphite. Therefore, it is necessary to characterize the nodular density on the fracture surface. To do that, a parameter representing the actual nodular density " $N s$ " was defined as follows:

$$
N s\left(\operatorname{nod} / \mathrm{mm}^{2}\right)=\frac{N}{S t}=\frac{N}{R s}
$$

In Eq. (4), " $N$ " is the actual number of nodules contained on the actual fracture surface "St", which corresponds to a projected surface unit of $1 \mathrm{~mm}^{2}$, as shown in Fig. 3(d). " $N$ " can be experimentally measured by using SEM or binocular magnifying lens. Each reported value of " $N$ " represents the average of the measurements performed on five different fields of each sample.

All the " $S t$ " values were obtained from the " $R s$ " experimental values, by Eq. (2).

The number of nodules in a flat metallographic surface defined as " $N n$ " is the conventional nodule count, which can be easily determined through a conventional metallographic procedure. Then the influence of the piece size can be taken into account through the difference " $N-N n$ " ${ }^{8)}$

\section{Results and Discussion}

\subsection{Roughness of the Fracture Profiles and Surfaces}

Table 1 summarizes the experimental values of the roughness parameters " $R L$ " and " $R s$ " obtained from the fracture surfaces of tensile and fracture toughness tested samples of several matrices and piece sizes. For an example, Fig. 5 graphically shows the variation of " $R s$ " for the four different matrices of the samples taken from the 1" Yblock. It can be seen that the values of " $R s$ " are similar for both the tensile and the rapid fracture areas of the tough- 
ness test samples, while they are clearly higher than that corresponding to the fatigued zone. Figure $\mathbf{6}$ shows the micrographies of the profiles observed on the different zones of a fracture toughness test sample having ferritic matrix.

The largest values of " $R s$ " found on the samples with ferritic matrices can be attributed to the higher plastic defor-

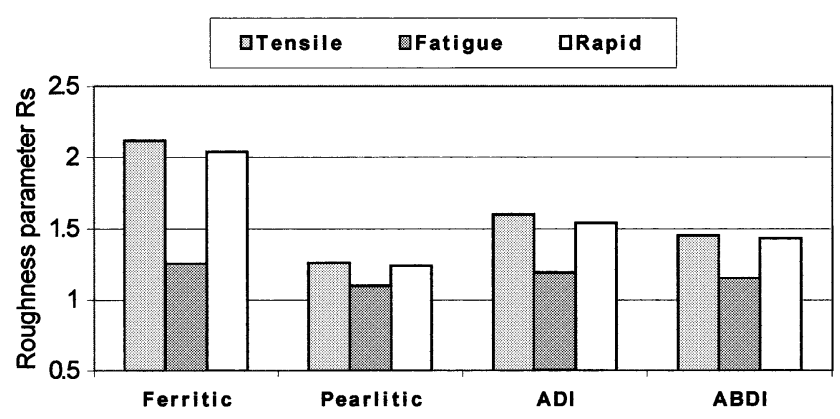

Fig. 5. Variation of values of the roughness parameter " $R s$ " on the three fracture surfaces in the four types of matrix. 1" Y-block.
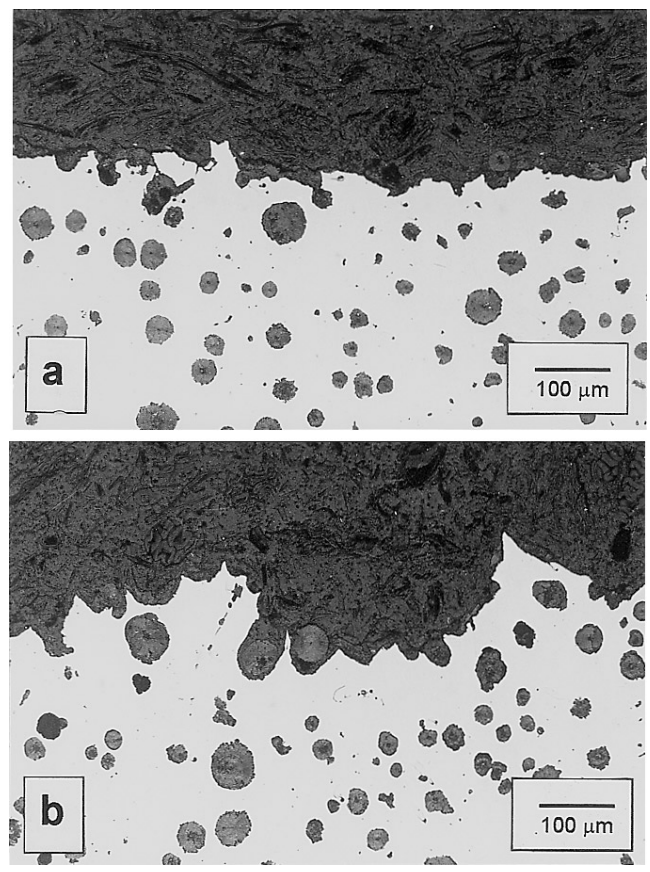

Fig. 6. Typical micrographies at $100 \mathrm{X}$ of the profiles in the fracture toughness: a) Fatigue zone (" $R L "=1.20$ ), b) Rapid fracture zone (" $R L "=1.82$ ). Ferritic matrix. 1 " Y-block. mation of this type of matrix.

The results summarized in Table 1 also indicate that the roughness of the fracture surface indicated by " $R L$ " and " $R s$ ", decreased slightly as the size of the piece increased from $1 / 2$ " to 2 ". The trends found from the experimental values of " $R s$ " are in agreement with observations reported in the literature."

" $R s$ " was also analytically determined by using the following empirical expression:

$$
R s=0.000012(N-N n)^{2}+0.00168(N-N n)+1
$$

This expression was obtained by mathematics regression by means of the " $N-N n$ " and " $R s$ " experimental values, in terms of the best-fit equation $\left(R^{2}=0.998\right)$.

\subsection{Nodular Density on the Fracture Surfaces}

Table 2 summarizes the results of the measurements of the parameter " $N$ ", the calculated values of " $N s$ ", and the values of the fracture surface "St" for all the studied cases. The experimental measurements of " $N$ " take into account both the visible nodules and the displaced ones (Fig. 7, arrows $\mathrm{A}$ and $\mathrm{B}$, respectively).

It was found that the values of " $N$ " decrease markedly when the piece thickness increases. This is due to the reduction in the value of " $N n$ " as the piece size increases. The values of " $N$ " in both tensile and fracture toughness surfaces are very similar. These values are larger than the values of " $N$ " found for the fatigue surfaces. These results are in agreement with observations indicated in the literature. ${ }^{5)}$

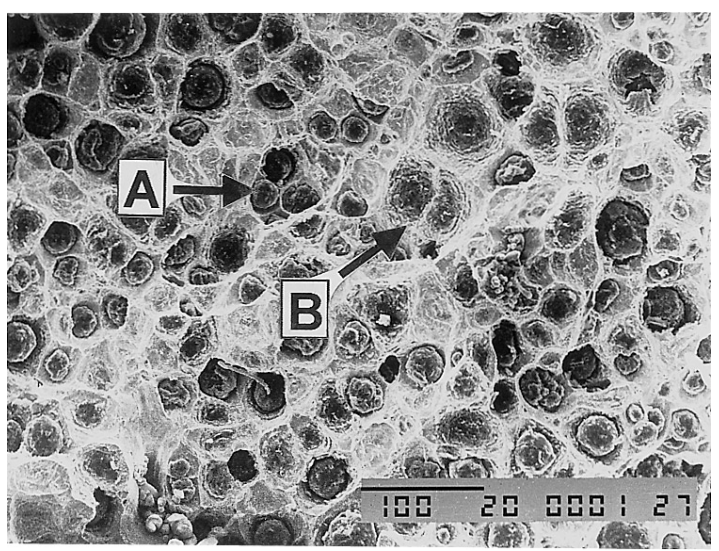

Fig. 7. Rapid fracture surface. Arrow A indicates visible nodules and arrow B indicates the place of the displaced nodule.

Table 2. Summary of actual number of nodules on fracture surface " $N$ ", fracture surface " $S t$ " (= " $R s$ ") and nodular density " $N s$ ", for all different types of test samples.

\begin{tabular}{|c|c|c|c|c|c|c|c|c|c|c|}
\hline \multirow[t]{3}{*}{ Matrix } & \multirow[t]{3}{*}{ Size } & \multirow{2}{*}{\multicolumn{3}{|c|}{ Tensile Test }} & \multicolumn{6}{|c|}{ Fracture Toughness Test } \\
\hline & & & & & & igue Fra & & & pid Fract & \\
\hline & & $\underset{\mathrm{Nod} / \mathrm{mm}^{2}}{\mathrm{~N}}$ & $\begin{array}{l}\mathrm{St}=\mathrm{RS} \\
\mathrm{mm}^{2} / \mathrm{mm}^{2}\end{array}$ & $\begin{array}{c}\mathrm{Ns} \\
\mathrm{Nod} / \mathrm{mm}^{2}\end{array}$ & $\begin{array}{c}\mathrm{N} \\
\mathrm{Nod} / \mathrm{mm}^{2}\end{array}$ & $\begin{array}{l}\mathrm{St}=\mathrm{RS} \\
\mathrm{mm}^{2} / \mathrm{mm}^{2}\end{array}$ & $\begin{array}{c}\mathrm{Ns} \\
\mathrm{Nod} / \mathrm{mm}^{2}\end{array}$ & $\begin{array}{c}\mathrm{N} \\
\mathrm{Nod} / \mathrm{mm}^{2}\end{array}$ & $\begin{array}{l}\mathrm{St}=\mathrm{RS} \\
\mathrm{mm}^{2} / \mathrm{mm}^{2}\end{array}$ & $\begin{array}{c}\mathrm{Ns} \\
\mathrm{Nod} / \mathrm{mm}^{2}\end{array}$ \\
\hline \multirow{3}{*}{ Ferritic } & $1 / 2^{\prime \prime}$ & 468 & 2.24 & 210 & 298 & 1.36 & 219 & 492 & 2.12 & 232 \\
\hline & $1^{\prime \prime}$ & 375 & 2.12 & 177 & 215 & 1.25 & 172 & 395 & 2.04 & 194 \\
\hline & $2^{\prime \prime}$ & 327 & 2.04 & 160 & 175 & 1.21 & 145 & 334 & 2.01 & 166 \\
\hline \multirow{3}{*}{ Pearlitic } & $1 / 2 "$ & 312 & 1.3 & 241 & 257 & 1.11 & 23 & 31 & 1.28 & 247 \\
\hline & $1^{\prime \prime}$ & 228 & 1.26 & 181 & 168 & 1.10 & 152 & 232 & 1.24 & 187 \\
\hline & $2 "$ & 185 & 1.22 & 152 & 150 & 1.09 & 138 & 190 & 1.21 & 157 \\
\hline \multirow{3}{*}{ ADI } & $1 / 2^{\prime \prime}$ & 380 & 1.67 & 228 & 270 & 1.23 & 220 & 390 & 1.60 & 244 \\
\hline & $1 "$ & 293 & 1.60 & 183 & 198 & 1.19 & 167 & 304 & 1.54 & 197 \\
\hline & $2^{\prime \prime}$ & 249 & 1.55 & 161 & 179 & 1.17 & 153 & 258 & 1.51 & 171 \\
\hline \multirow{3}{*}{ ABDI } & $1 / 2 "$ & 349 & 1.49 & 235 & 260 & 1.19 & 21 & 35 & 1.47 & 242 \\
\hline & $1^{\prime \prime}$ & 266 & 1.45 & 184 & 179 & 1.15 & 156 & 274 & 1.43 & 192 \\
\hline & 2" & 216 & 1.36 & 158 & 165 & 1.10 & 150 & 220 & 1.36 & 162 \\
\hline
\end{tabular}


Table 3. Conventional nodular count ("Nn"), actual number of nodules on fracture surfaces (" $N$ "), roughness (" $R s ")$, nodular density ("Ns") and difference " $N-N n$ ", for tensile test samples.

\begin{tabular}{|c|c|c|c|c|c|c|}
\hline Size & Matrix & $\begin{array}{c}\mathrm{Nn} \\
\mathrm{Nod} / \mathrm{mm}^{2}\end{array}$ & $\begin{array}{c}\mathrm{N} \\
\mathrm{Nod} / \mathrm{mm}^{2}\end{array}$ & $\begin{array}{c}\mathrm{Rs} \\
\mathrm{mm}^{2} / \mathrm{mm}^{2} \\
\end{array}$ & $\begin{array}{c}\mathrm{Ns} \\
\mathrm{Nod} / \mathrm{mm}^{2}\end{array}$ & $\begin{array}{l}\mathrm{N}-\mathrm{Nn} \\
\mathrm{Nod} / \mathrm{mm}^{2}\end{array}$ \\
\hline \multirow{4}{*}{$1 / 2 "$} & Ferritic & \multirow{4}{*}{203} & 468 & 2.24 & 209 & 265 \\
\hline & Pearlitic & & 312 & 1.30 & 241 & 109 \\
\hline & $\mathrm{ADI}$ & & 380 & 1.67 & 228 & 177 \\
\hline & ABDI & & 349 & 1.49 & 235 & 146 \\
\hline \multirow{5}{*}{$1^{\prime \prime}$} & Ferritic & \multirow{4}{*}{127} & 375 & 2.12 & 177 & 248 \\
\hline & Pearlitic & & 228 & 1.26 & 181 & 101 \\
\hline & ADI & & 293 & 1.60 & 183 & 166 \\
\hline & ABDI & & 266 & 1.45 & 184 & 139 \\
\hline & Ferritic & \multirow{4}{*}{93} & 327 & 2.04 & 160 & 234 \\
\hline \multirow{3}{*}{$2^{\prime \prime}$} & Pearlitic & & 185 & 1.22 & 152 & 92 \\
\hline & ADI & & 249 & 1.55 & 161 & 156 \\
\hline & ABDI & & 216 & 1.36 & 158 & 123 \\
\hline
\end{tabular}

Table 4. Experimental values of " $N-N n$ ", " $R s$ ", and actual mechanical properties (elongation $(\delta)$, tensile strength (UTS) and fracture toughness $\left(K_{\mathrm{IC}}\right)$ ), determined on test samples.

\begin{tabular}{|c|c|c|c|c|c|c|}
\hline Matrix & Size & $\begin{array}{c}\mathrm{N}-\mathrm{Nn} \\
\mathrm{Nod} / \mathrm{mm}^{2}\end{array}$ & $\begin{array}{c}\mathrm{St}=\mathrm{Rs} \\
\mathrm{mm}^{2} / \mathrm{mm}^{2}\end{array}$ & $\begin{array}{l}\delta \\
\% \\
\end{array}$ & $\begin{array}{l}\text { UTS } \\
\mathrm{MPa}\end{array}$ & $\begin{array}{r}\mathrm{K}_{\mathrm{lC}} \\
\mathrm{MPam}^{1 / 2}\end{array}$ \\
\hline \multirow{3}{*}{ Ferritic } & $1 / 21$ & 265 & 2.24 & 19 & 470 & 54 \\
\hline & $1^{\prime \prime}$ & 248 & 2.12 & 18 & 462 & 56 \\
\hline & $2^{\prime \prime}$ & 234 & 2.04 & 17 & 450 & 50 \\
\hline \multirow{3}{*}{ ADI } & $1 / 2 "$ & 177 & 1.67 & 13 & 1140 & 75 \\
\hline & $1^{\prime \prime}$ & 166 & 1.60 & 11 & 1135 & 76 \\
\hline & $2 "$ & 156 & 1.55 & 9 & 1120 & 72 \\
\hline \multirow{3}{*}{ ABDI } & $1 / 2 "$ & 146 & 1.49 & 6 & 1588 & 64 \\
\hline & 1" & 139 & 1.45 & 5 & 1575 & 65 \\
\hline & $2^{\prime \prime}$ & 123 & 1.36 & 4 & 1550 & 60 \\
\hline \multirow{3}{*}{ Pearlitic } & $1 / 2 "$ & 109 & 1.30 & 7 & 993 & 58 \\
\hline & 1" & 101 & 1.26 & 6 & 977 & 58 \\
\hline & $2^{\prime \prime}$ & 92 & 1.22 & 5 & 960 & 48 \\
\hline
\end{tabular}

The results summarized in Table 3 indicate that the actual nodular density of the fracture surface " $N s$ " decreases markedly as the piece size increases. On the other hand, "Ns" is not significantly influenced by the matrix and the type of test in the case of samples taken from the same piece size.

\subsection{Relationship between Roughness and Mechanical Properties}

Table 4 lists the values of elongation, tensile strength and fracture toughness obtained in the mechanical tests performed on all the studied samples taken from Y-blocks of different sizes and having different matrices. The experimental values of the fracture roughness " $R s$ " for each test sample are also listed in Table 4.

Through mathematical regression, the following relationship between roughness and mechanical properties were founded:

a) Elongation

$$
\delta(\%)=15 R s-14 .
$$

b) Tensile Strength

$\operatorname{UTS}(\mathrm{Mpa})=7454 R s^{3}-39845 R s^{2}+68638 R s-37067$
Table 5. Comparison between mechanical properties calculated by using the empirical expressions of other castings tested by other researchers.

\begin{tabular}{|c|c|c|c|c|c|c|c|c|}
\hline \multirow[t]{2}{*}{ Matrix } & \multirow[t]{2}{*}{$\begin{array}{l}\mathrm{N}-\mathrm{Nn} \\
\mathrm{Nod} / \mathrm{mm}^{2}\end{array}$} & \multicolumn{3}{|c|}{$\begin{array}{l}\text { Experimental values } \\
\text { reported by other authors }\end{array}$} & \multirow[t]{2}{*}{ Ref. } & \multicolumn{3}{|c|}{ Calculated values } \\
\hline & & $\begin{array}{l}\delta \\
\%\end{array}$ & $\begin{array}{l}\text { UTS } \\
\mathrm{MPa}\end{array}$ & $\begin{array}{c}\mathrm{K}_{\mathrm{IC}} \\
\mathrm{MPam}^{1 / 2}\end{array}$ & & $\begin{array}{l}\delta \\
\%\end{array}$ & $\begin{array}{l}\text { UTS } \\
\mathrm{MPa}\end{array}$ & $\begin{array}{r}\mathrm{K}_{\mathrm{IC}} \\
\mathrm{MPam}^{1 / 2}\end{array}$ \\
\hline $\begin{array}{c}\text { ADI } \\
\text { Grade } 2\end{array}$ & 171 & 11.9 & 1113 & 70 & $\begin{array}{c}\text { Martínez } \\
\text { et al }^{9}\end{array}$ & 10.6 & 1214 & 74 \\
\hline $\begin{array}{c}\text { ADI } \\
\text { Grade } 4\end{array}$ & 128 & 3.2 & 1597 & 63 & & 7.2 & 1393 & 64 \\
\hline $\begin{array}{c}\text { ADI } \\
\text { Grade } 1\end{array}$ & 178 & 14.2 & 1156 & Unreported & $\begin{array}{c}\text { Rivera et } \\
\text { al }^{10)}\end{array}$ & 11.2 & 1132 & 74 \\
\hline Pearlitic & 103 & 4.5 & 1102 & & & 5.5 & 1202 & 56 \\
\hline
\end{tabular}

c) Fracture Toughness

$$
\begin{aligned}
& K_{\mathrm{IC}}\left(\mathrm{MPa} \mathrm{m}^{1 / 2}\right)=368 R s^{4}-2430 R s^{3}+5834 R s^{2} \\
& -6015 R s+2304
\end{aligned}
$$

In order to analyse the validity of expressions 6 to 8 for other cases, these formulas were applied to evaluate the mechanical properties of other cast iron samples tested by other authors, ${ }^{9,10)}$ through the analysis of their surfaces. The fracture surfaces parameters were obtained using the methodology developed in the present research. The calculated values of surface roughness were introduced into the empirical equations in order to calculate the mechanical properties of elongation, tensile strength and fracture toughness. Then the results were compared with the actual values reported by Martínez et al. ${ }^{9)}$ and Rivera et al. ${ }^{10)}$ Table 5 shows that the predicted values obtained by using the empirical expressions are in good agreement with the mechanical properties obtained experimentally by those other researchers.

The technological importance of this method is that it could allow to estimate the critical levels of stress and deformation which took place in a region of a broken piece, by means of its fracture surface analysis. Therefore, this topographic method might constitute a way for quality control and design of ductile iron parts. In order to ensure its technological validity, the method must be improved by contrasting and adjusting with new data taken from other several broken parts. The current development is considered only as a first step in the qualitative and quantitative study of fracture surfaces.

\section{Conclusions}

The roughness of the fracture surfaces of tensile and fracture toughness tested samples of ductile iron having a variety of matrices and piece sizes, were characterized by using topographic parameters.

The main fracture parameters are the fracture roughness " $R s$ " and the actual nodular density " $N s$ ". It was found that " $R s$ " increases as the ductility of the material increases. On the other hand, "Ns" is largely dependent of the conventional nodular count of the piece under study, but it does not vary with the type of test and matrix.

The roughness " $R s$ " was also analytically determined through the experimental parameters " $N-N n$ " which take into acount the effect of the piece size on nodule count.

Empirical expressions that could allow to predict critical stress and elongation from fracture surface observations were found by relating the values of " $R s$ " to experimental 
values of the mechanical properties of elongation, tensile strength and fracture toughness. These empirical expressions were tested through other fractured samples and experimental values reported by other authors, reaching good agreements.

The fracture surface topography quantification developed in this work could be the first step of a quality control and design methodology of technological interest.

\section{REFERENCES}

1) G. Zambelli and L. Haenny: AFS Trans., 37 (1982), 297.

2) W. Villasís and J. Sikora: Cast Met., 1 (1989), 210.
3) G. Greno: Doctoral Thesis, National University of Mar del Plata, Argentina, (1997), 1.

4) N. Lazardis, R. Nanstad, F. Worzala and C. Loper: AFS Trans., 51 (1977), 277.

5) H. Mead and W. Bradley: AFS Trans., 116 (1980), 265.

6) E. Underwood and K. Banerji: Metal Handbook, 9th ed., Vol. 12, ASM, Metals Park, OH, (1987), 211.

7) E. Underwood and K. Banerji: Metal Handbook, 9th ed., Vol. 12, ASM, Metals Park, OH, (1987), 193.

8) V. Bermont: Doctoral Thesis, National University of Mar del Plata, Argentina, (2000), 1.

9) R. Martinez, R. Boeri and J. Sikora: AFS Trans., 8 (1998), 27.

10) G. Rivera, R. Boeri and J. Sikora: Int. J. Cast Metals Res., 11 (1999), 533. 